\title{
A distinção aristotélica entre Lógica, Dialética e Retórica e seu lugar na Teoria da Argumentação*
}

\section{Lilian Bermejo-Luque}

Docente da Universidade de Granada, Espanha

https://orcid.org/0000-0002-2385-6026

Tradução:

Eduardo Lopes Piris

Universidade Estadual de Santa Cruz

Resumo: Devemos considerar a obra de Aristóteles como a origem da Teoria da Argumentação ou como um obstáculo que explicaria parcialmente o desenvolvimento tardio desta teoria? Neste artigo, tento mostrar que existem boas razões para defender ambas as posições. Com isso, pretendo ilustrar uma certa forma de conceber as relações entre Lógica, Dialética e Retórica. Essa concepção estaria mais próxima dos objetivos da própria Teoria da Argumentação do que a visão fragmentária que, por séculos, se viu apoiada pelo trabalho daqueles que, a partir de uma ou outra disciplina, se ocuparam do estudo normativo da argumentação. À medida que essa visão fragmentária é uma herança daquela visão que ainda não se desfez inteiramente na moderna Teoria da Argumentação, a leitura das obras aristotélicas aqui proposta tenta fornecer elementos úteis de reflexão para o nosso trabalho atual, especialmente aqueles relacionados à concepção da Lógica como uma teoria normativa de inferência e do entimema como silogismo retórico.

Palavras-chave: Órganon aristotélico. Dialética. Lógica. Retórica. Teoria da Argumentação.

Abstract: Should we consider Aristotle's work on argumentation as the origins of Argumentation Theory or rather as an obstacle that, at least in part, would explain its late emergence and development? In this article I try to show that, in fact, there are good reasons to defend both views. By doing so, I aim to illustrate a certain way of thinking of the relationships between Logic, Dialectic and Rhetoric. Such conception of the relationships between these disciplines would be more suitable for the goals of Argumentation Theory than the fragmentary view that, for centuries, has been endorsed by most scholars working on each of them. As long as this fragmentary view has been inherited up to our days, our proposed reading of Aristotle's texts aims to offer some conceptual elements for current developments, mostly regarding the conceptions of Logic as the normative theory of inference and of the enthymeme as the rhetorical syllogism.

Keywords: Aristotle's Organon. Dialectics. Logic. Rhetoric. Argumentation Theory.

\footnotetext{
* A Revista EID\&A agradece vivamente o Professor Francisco Pizarro, diretor da Revista Cogency, e a Professora Lilian Bermejo-Luque, autora, por autorizarem a publicação da tradução deste artigo encontrado originalmente em Cogency, v. 1, n. 2, 2009.
} 


\section{Introdução}

Devemos considerar a obra de Aristóteles como a origem da Teoria da Argumentação ou como obstáculo que implicaria parcialmente seu desenvolvimento tardio? Como tentarei mostrar nas páginas seguintes, penso que há boas razões para defender ambas as posições.

Embora isso possa ser visto como uma questão histórica interessante em si mesma, o que pretendo, ao considerar o papel da obra de Aristóteles em relação à Teoria da Argumentação, é antes ilustrar certo modo de conceber as relações entre Lógica, Dialética e Retórica. Acredito que tal concepção se aproxima mais dos objetivos da própria Teoria da Argumentação do que a visão fragmentária que, por séculos, se viu apoiada pelo trabalho daqueles que, a partir de uma ou outra disciplina, se ocuparam do estudo normativo da argumentação.

Mais ainda, considerando que essa visão fragmentária é uma herança da qual a moderna teoria da argumentação ainda não se desfez completamente, a leitura das obras aristotélicas que aqui se propõe visa a contribuir com elementos úteis de reflexão para o nosso trabalho atual. É por isso que o que segue pretende ser de interesse mais conceitual do que historiográfico: não se trata de apresentar uma tese sobre a "verdadeira" interpretação da obra aristotélica, mas sim de oferecer uma perspectiva distinta que nos permita considerar até que ponto a interpretação tradicional não se encontra enviesada, pelo menos em parte, pelas mesmas contingências históricas que postergaram o desenvolvimento da Teoria da Argumentação.

Como se sabe, as origens da Teoria da Argumentação enquanto disciplina acadêmica são bastante recentes. Em meados da segunda metade do século passado, autores como Chaïm Perelman e Lucie Olbrechts-Tyteca (1958), Stephen Toulmin (1958) e Charles Hamblin (1970) enfatizaram o interesse e as idiossincrasias do estudo normativo da argumentação em linguagem natural. O desenvolvimento da Teoria da Argumentação aglutinou assim os esforços daqueles que, seja de uma perspectiva Lógica, Dialética ou Retórica, interessaram-se pelas condições do bem argumentar.

Assim, em Acts of Arguing, Christopher Tindale (1999) levantou as observações de Joseph Wenzel (1979) e Jürgen Habermas (1984), para identificar a distinção aristotélica entre Lógica, Dialética e Retórica a três diferentes concepções da argumentação como objeto de estudo. De acordo com Tindale, tratar-se-ia, respectivamente, do argumento enquanto (1) produto da comunicação 
argumentativa, (2) procedimento de troca comunicativa que implica certo tipo de prática argumentativa e (3) processo no qual tal prática se implementa.

A Lógica está preocupada com os produtos PPC (premissas-conclusão) da argumentação, os textos e discursos em que são feitas afirmações com as evidências de apoio, as quais podem ser julgadas como válidas ou inválidas, fortes ou fracas. A Dialética se interessa por regras ou procedimentos que são necessários para o argumento a ser feito corretamente e atingir seus objetivos de resolução de disputas e promoção discussões críticas. A retórica se concentra nos processos comunicativos inerente à argumentação, nos meios usados pelos falantes para obter a adesão do público às suas afirmações (TINDALE, 1999, p. 3-4).

O objetivo principal deste trabalho é oferecer uma leitura da obra de Aristóteles que mostre que o tradicional desencontro entre os três saberes - a Lógica, a Dialética e a Retórica - que compõem o estudo normativo da argumentação não é uma consequência natural da obra aristotélica, mas que tem a ver com a maneira como ela foi recebida, tendo em conta o interesse que o próprio Aristóteles manifestou por um desses saberes e o modo como este se desenvolveu posteriormente.

\section{Teorias lógicas, dialéticas e retóricas da argumentação}

Atualmente, a Teoria da Argumentação contém propostas representativas das perspectivas lógica, dialética e retórica. As concepções da argumentação das quais partem cada uma dessas propostas têm como objetivo comum servir de base para uma teoria normativa para o fenômeno ordinário da argumentação. Assim, por exemplo, o próprio Tindale elabora seu modelo a partir de uma concepção de argumentação como processo, pois, em sua opinião, isso permite uma visão integral, o que seria inacessível com base em outros pressupostos. Por isso, ele propõe uma recuperação do trabalho de Perelman, e do que podemos chamar de perspectiva retórica da Teoria da Argumentação.

Por sua vez, a proposta mais representativa da perspectiva lógica dentro da Teoria da Argumentação, a chamada Lógica Informal Canandense, reúne um conjunto de trabalhos desenvolvidos desde a década de 1970, principalmente por Trudy Govier, John Anthony Blair e Ralph H. Johnson, que dedicam-se a constituir uma lógica não formal para argumentos em linguagem natural, já que, segundo esses autores, uma perspectiva retórica afigura-se insuficientemente normativa. Seu ponto de partida foi o reconhecimento dos limites da Lógica Formal para lidar com as falácias argumentativas e com a dimensão dialética da argumentação. 
Por fim, a perspectiva dialética seria representada principalmente pela Pragmadialética, também chamada de "Escola de Amsterdã", cujo trabalho fundamental, Speech Acts in Argumentative Discussions, de Frans H. van Eemeren e Rob Grootendorst (1984), desenvolve uma concepção de argumentação como procedimento de discussão crítica que tem como objetivo resolver racionalmente uma diferença de opinião. A concepção dialógica da argumentação também representou o ponto de partida de diferentes sistemas de dialética formal, tais como o de Else Barth e Erik Krabbe (1982), e uma característica fundamental da obra de Douglas Walton (1989) e Douglas Walton e Erik Krabbe (1995).

Devido aos seus distintos focos de interesse - isto é, os argumentos, os procedimentos de troca argumentativa ou os processos de comunicação argumentativa -, pode parecer que as teorias que compõem atualmente a disciplina não são, absolutamente, propostas concorrentes, mas são. Como projeto geral, a Teoria da Argumentação é uma tentativa de oferecer um modelo normativo adequado para dar conta do fenômeno da argumentação cotidiana, e as diferentes perspectivas não caracterizam modelos paralelos ou complementares, mas sim concorrentes, uma vez que cada teoria afirma ter encontrado o ponto de partida ideal para lidar com esse fenômeno. Certamente, ao definir a argumentação de um modo ou de outro, essas teorias definem seu próprio objeto de estudo. Mas a representatividade desse objeto no que tange ao tipo de fenômeno cujas condições normativas devem ser analisadas apresenta-se, então, como um critério essencial tanto para decidir sobre o valor teórico e prático de tais teorias quanto para comparar modelos cujos objetos, em princípio, diferem entre si.

\section{O lugar da obra de Aristóteles}

Apesar de, nos últimos tempos, o mero aparecimento da Teoria da Argumentação ter conseguido integrar em uma única disciplina as distintas áreas do estudo normativo da argumentação em linguagem natural, é verdade que aí subjaz a ideia de que a Lógica, a Dialética e a Retórica são, na melhor das hipóteses, perspectivas alternativas.

Mesmo reconhecendo, com justiça, os esforços de diferentes teorias para incluir elementos alheios ao seu ponto de partida, não se articulou ainda uma proposta capaz de integrar essas três disciplinas, enquanto perspectivas complementares, para a elaboração de um modelo do bem argumentar. 
Qual é então a causa dessa fragmentação que nem mesmo o importante desenvolvimento experimentado pela Teoria da Argumentação nas últimas décadas conseguiu superar ainda? Na minha opinião, para encontrar uma resposta, deveríamos indagar, em grande medida, a evolução histórica do modo como ocorreu a recepção dos estudos aristotélicos sobre argumentação e o posterior estabelecimento da Lógica, Dialética e Retórica como disciplinas consolidadas e completamente independentes entre si.

Dito isso, como pretendo mostrar a seguir, este resultado não deve ser visto como uma consequência "intrínseca" das propostas aristotélicas em si, mas compreender de que maneira seria possível considerá-lo fruto de certas contingências históricas; entre elas, aquelas que determinaram o papel de Aristóteles como o pai do que, mais tarde, se constituiu como Lógica Formal.

Como argumentei em Bermejo-Luque (2008; 2009), a preponderância da Lógica Formal constituiu um verdadeiro obstáculo ao desenvolvimento da Teoria da Argumentação, promovendo a crença de que um modelo normativo para argumentação na linguagem natural não era nada mais do que o resultado da adição, aos sistemas lógicos formais, de uma teoria adequada para a formalização de argumentos reais. Durante séculos, a normatividade argumentativa passou a ser equiparada à normatividade lógica, entendida, sobretudo, como algo de natureza meramente formal. Essa visão deixou de fora os condicionamentos pragmáticos da argumentação enquanto atividade comunicativa. Por exemplo, tudo o que estava relacionado com o estudo das falácias informais aparecia, quando muito, como um capítulo pitoresco e assistemático em alguns manuais sensíveis à questão da aplicabilidade da Lógica para a avaliação da argumentação cotidiana.

Dado esse preconceito, não é surpreendente que, até o surgimento do Teoria da Argumentação, pensava-se que a contribuição mais importante de Aristóteles para o estudo normativo da argumentação consistia em que ele teria firmado as bases da Lógica como uma teoria formal da inferência válida. Certamente, o próprio Aristóteles parece considerar a silogística analítica dos Analíticos Anteriores ${ }^{1}$ como o núcleo dessa empreitada e seus estudos sobre as categorias, as proposições e os juízos constituiriam elementos complementares a essa obra, mas, ao contrário, obras como Retórica e Refutações Sofísticas - esta sobre falácias informais - seriam, na melhor das hipóteses, reflexos adicionais, quando não meros elementos estranhos ao programa de

\footnotetext{
${ }^{1}$ N.T.: Para consulta às obras de Aristóteles aqui citadas, exceto a Retórica, indicamos a edição brasileira:

ARISTÓTELES. Órganon: Categorias, Da interpretação, Analíticos Anteriores, Analíticos Posteriores, Tópicos, Refutações Sofísticas. 2.ed. rev. Tradução do grego, textos adicionais e notas de Edson Bini. Bauru: EDIPRO, 2010.
} 
elaboração de uma ciência formal para a avaliação dos argumentos. Tal concepção de sua obra tornaria Aristóteles o pai da Lógica Formal contemporânea, contudo, à medida que essa disciplina foi sendo apresentada, por séculos, como o único modelo propriamente normativo possível para a argumentação, Aristóteles teria sido antes um obstáculo para o desenvolvimento da Teoria da Argumentação, tal qual a conhecemos hoje.

Ora, seria esta a única leitura possível da obra aristotélica sobre argumentação? Na minha opinião, também é possível ver a silogística analítica tão somente como uma parte de um todo maior, cujo núcleo não é inferência formal, mas sim a prática da argumentação enquanto instrumento para a Filosofia e conhecimento. Deste ponto de vista, o conjunto de obras que Andrônico de Rodes teria reunido sob o título Organon, "Instrumento", representaria a missão de fundar metodologicamente o empreendimento teórico aristotélico, mais do que acompanhar e complementar a elaboração de uma ciência formal sobre o método. Para essa empreitada, não apenas a silogística analítica mas também as reflexões aristotélicas sobre a Dialética, os tópicos e as falácias seriam peças fundamentais às quais teriam de ser adicionadas as reflexões da Retórica e até - como sugerido por Covarrubias (2006) - da Poética aristotélica: assim, tal projeto, como um todo articulado, ocupar-se-ia da comunicação argumentativa em geral e não somente da teoria da prova e inferência formal.

É verdade que, de um ponto de vista meramente histórico, a primeira dessas interpretações da obra de Aristóteles seria a mais precisa. Isso certamente explicaria por que, depois de Aristóteles, o estudo da argumentação ficou dividido em três disciplinas que tiveram desdobramentos muito distintos: por um lado, a Lógica, que se desenvolveu sob a influência de silogística analítica, evoluiu como um conjunto de teorias formais sobre a inferência válida; por outro lado, a Retórica, que após percorrer uma longa jornada, acabou quase esquecida e parcialmente desacreditada por sua suposta preferência pelo ornamento em detrimento do argumento; e, finalmente, o estudo das falácias formais, um assunto que - praticamente até os trabalhos de Hamblin (1970) sobre Dialética - não havia recebido tratamento sistemático algum.

No entanto, caberia questionar essa evolução a partir de uma perspectiva moderna da Teoria da Argumentação, destacando que a concepção aristotélica de argumentação era suficientemente ampla para considerar não apenas que o argumentos são o meio por excelência de justificar nossas afirmações e crenças, mas também que a argumentação é frequentemente usada para tentar persuadir os outros conforme aquilo que afirmamos e acreditamos. 
Não pretendo fazer desta intuição uma tese sobre a interpretação adequada da obra de Aristóteles sobre argumentação. Mas, ao menos, eu gostaria de mostrar que faz sentido ler Aristóteles desta forma e que, além disso, esta leitura permite compreender mais fecundamente as relações entre Lógica, Dialética e Retórica.

\section{Platão e o estereótipo da oposição entre Dialética e Retórica}

As primeiras reflexões teóricas sobre a argumentação constituiram, por sua vez, uma primeira demarcação entre a Dialética e a Retórica. Como se sabe, o modo de conceber as relações entre discurso e verdade articulou, nos tempos de Sócrates e Platão, o debate ético-político e epistemológico entre sofistas e filósofos, o que pode ser considerado como a origem do estudo normativo da argumentação. Tradicionalmente, a oposição entre as propostas sofistas e as de Sócrates ou Platão foi representada como a contraposição entre os defensores da Retórica e os defensores da Dialética, respectivamente concebidas como disciplinas com um interesse meramente instrumental na argumentação e no discurso, em face de uma disciplina teórica que vê a argumentação e o discurso como o próprio método do conhecimento. Em todo caso, essas eram as premissas logocêntricas da reflexão grega.

É um lugar comum opor sofistas a filósofos, dizendo que, em vez de um compromisso com a verdade e o conhecimento, os sofistas tinham um compromisso com seus clientes, a quem eles treinaram nas artes do discurso como forma de prosperar em um contexto social e político que havia elevado a arte do discurso a meio de interação pública por excelência e até mesmo a um espetáculo em si. Contrariamente, a Sócrates, e especialmente a Platão, essa concepção de discurso como espetáculo teria bastado para tornar os sofistas culpados da acusação geral de preferir a simples opinião ao verdadeiro conhecimento. Essa caricaturização das relações entre sofistas e filósofos seria a base da ulterior concepção pejorativa da Retórica como "arte da persuasão": para Platão, a Retórica seria um mero instrumento - nem mesmo uma arte, pois careceria de um objeto próprio - para desenvolver a duvidosa habilidade de confundir auditórios eficazmente, apresentando como verdadeiro o que somente é opinável. Pelo menos, essa é a visão estereotipada das suspeitas de Platão contra a Retórica.

Platão certamente opôs a confiabilidade da Dialética à maleabilidade da Retórica, destacando a diferença entre a aquisição de conhecimento e a mera promoção de crenças mais ou menos populares e corretas. Com efeito, esse é um dos principais 
temas desenvolvidos em diálogos como Górgias e Fedro. Mas, para inferir disso uma preferência da parte de Platão, deveríamos pressupor que ambas as disciplinas seriam comparáveis em seus resultados, ao perseguir os mesmos objetivos. No entanto, tal hipótese parece contradizer outro dos estereótipos sobre a filosofia platônica, a saber, a ideia de que a Dialética era o método por excelência para alcançar o conhecimento, enquanto a Retórica seria apenas um conjunto desarticulado de técnicas destinadas ao treinamento das habilidades persuasivas: uma disciplina de tão curto alcance não poderia representar por si só uma ameaça ao conhecimento.

Por sua vez, autores como James Benjamin (1997) ou Charles Griswold (2004) têm argumentado que Platão teria reconhecido explicitamente a natureza retórica de toda comunicação, distinguindo entre boas e más práticas da arte de apresentar discursos. Assim, à luz de textos como o Livro III da República, em que Platão parece não se importar tanto com o que deve ser dito mas com a maneira que deve ser dito, encontramos certa concessão: uma importante função para a "boa" Retórica dentro de seu grande projeto político, que se baseava na promoção da educação (paideia) adequada a cada grupo social. Assim, embora tivesse tratado de nos prevenir contra a perversão da arte do discurso praticada pelos sofistas, Platão não estaria simplesmente opondo a Retórica à Dialética, pois mesmo os grupos destinados a receber o verdadeiro conhecimento teriam de avançar em sua educação, entre outras coisas, graças às habilidades discursivas de seus mestres. Além disso, no Górgias, Platão até chega a falar de uma verdadeira Retórica cujo objetivo não seria produzir o maior prazer do auditório, mas sim produzir o que é o bem maior por meio de sua verdade (PLATO, 451d-452d-e).

\section{Lógica e Dialética na perspectiva da Retórica de Aristóteles}

Longe da cautelosa avaliação da retórica que encontramos em Platão, Aristóteles, como se sabe, dedicou um tratado à Retórica e, com isso, pode lhe garantir o caráter de disciplina autônoma, o que Platão havia tentado evitar. Mas também é verdade que, nas primeiras linhas da Retórica, ele insiste em que, apesar de considerála uma arte, esta seria uma contraparte da Dialética, com a qual compartilharia a falta de um conteúdo específico, a independência dos princípios das ciências, o destino da consideração do provável, da opinião, do possível, a incessante remissão aos dois lados de qualquer assunto. Para Aristóteles, mais do que ciências, Dialética e Retórica seriam técnicas que podem ser aplicadas a qualquer conhecimento, o que é coerente com a 
ideia de que seu interesse pela argumentação remete a inquietações metodológicas mais que ao desejo de elaborar uma ciência - no sentido de um saber demonstrativo semelhante à Lógica Formal contemporânea.

Segundo a leitura tradicional, mais que opor entre si a Dialética e a Retórica, Aristóteles oporia ambas as disciplinas à Lógica enquanto ciência da demonstração, sustentando que esta se refere à verdade, enquanto a Dialética e a Retórica versam sobre o plausível. Entretanto, também está subjacente às suas reflexões sobre a argumentação como prática a ideia de que, em geral, avaliar qualquer argumento é agir por meio do mesmo tipo de faculdade, a saber, a faculdade de julgar se algo deve ou deveria ser conveniente, dadas certas condições. Nessa perspectiva, à Lógica caberia determinar a correção desses juízos enquanto inferências, ao passo que a Retórica estaria preocupada em estudar a maneira pela qual podemos induzir tais juízos nos outros, a fim de persuadi-los. Por sua vez, a Dialética teria como objetivo determinar a aceitabilidade dos princípios e evidências dos quais partimos no momento de elaborar tais juízos, pois, como instrumento para o conhecimento, sua função é a de ver quais das nossas opiniões (endoxa) são capazes de resistir ao exame cuidadoso.

Desse modo, haveria, na opinião de Aristóteles, uma antítese entre os objetivos persuasivos que motivam a Retórica e os propósitos científicos da Dialética e da Lógica como instrumentos para a demonstração? O certo é que, no Capítulo I da Retórica, Aristóteles começa criticando aqueles que, estudando a arte do bem dizer, somente se ocupam, porém, daquilo que é mais acessório nos discursos, em vez de se preocuparem com o argumento, que deveria ser o seu foco. Em seguida, assinala que existem argumentos dialéticos e retóricos, sendo que a principal diferença entre estes e os argumentos demonstrativos é que os primeiros apenas chegam a deduções prováveis, e não necessárias. À luz dessas observações, parece que, ao contrário, o que Aristóteles faz é mostrar que a Lógica (entendida como a teoria da inferência), a Dialética e a Retórica estão igualmente preocupadas com as condições normativas da argumentação. A complementaridade dessas disciplinas seria um reflexo da compatibilidade que Aristóteles vê entre persuasão e justificação. E seria precisamente a duplicidade do argumento como instrumento para justificar e para persuadir que o tornaria um elemento chave tanto no momento de estabelecer e transmitir o conhecimento no âmbito da ciência quanto no momento de nos conduzir racionalmente no âmbito das decisões ético-políticas.

Assim, ao contrário de Platão, Aristóteles não iria apenas encontrar nenhuma oposição entre persuadir e justificar, mas assumiria que se chega à persuasão ao oferecer ao juízo dos outros que as coisas são desta ou daquela maneira. Nessa tarefa, 
a credibilidade do orador e as emoções do auditório certamente desempenham um papel fundamental, mas também tem parte nisso a força do argumentos empregados. O ethos do orador, o pathos do auditório e do logos do próprio discurso são igualmente constitutivos do ato argumentativo, de modo que todos eles determinariam as condições do bem dizer, não apenas no que se refere à sua capacidade de persuadir os outros, mas também à sua capacidade de justificar, de mostrar que certas afirmações são corretas.

Idealmente, em um processo de comunicação, trata-se de persuadir que algo é verdadeiro. Mas, muitas vezes, nossas afirmações só podem ser propostas como plausíveis ou razoáveis. Para Aristóteles, essa é, de fato, nossa situação em grande parte dos assuntos importantes. Entretanto, a racionalidade também deve ser acessível nestes casos: as decisões corretas sobre em que acreditar e o que fazer são levadas a cabo à luz de bons argumentos. A Retórica, como campo de estudo do discurso enquanto mecanismo persuasivo, inclui o estudo dos argumentos que são usados para persuadir uns aos outros sobre questões em que a prova e a demonstração são elusivas e a busca pela verdade tem de abrir caminho para a busca da verossimilhança. Mas esta observação não possui as conotações negativas com as quais a filosofia platônica permeia a ideia de opinião: no uso da razão, descartamos o falso, de modo que a verdade se coloca como horizonte, porque, para Aristóteles, as coisas verdadeiras e melhores são, por natureza, bem mais aptas à inferência e mais persuasivas.

Desse modo, ainda que o objetivo da Retórica não seja o conhecimento, mas sim a persuasão, Aristóteles assume - como Platão em várias passagens - que dizer a verdade é inútil se não tivermos meios eficazes para persuadir os demais a seu respeito. Portanto, não haveria conflito, mas correspondência entre conhecimento e Retórica, como haveria entre a ciência de um médico e os conselhos que ele pode dar ao seu paciente, como assinalava o próprio Platão. No entanto, em Aristóteles, encontramos razões mais importantes para defender a legitimidade da Retórica. Em primeiro lugar, sua visão de nossa capacidade de preservar a racionalidade, mesmo em campos em que a demonstração não é possível: o conhecimento e a verdade muitas vezes permanecem fora de nosso alcance, mas ainda podemos aspirar a formar crenças corretas, conduzindo nossas opiniões de maneira adequada. Mas, mais significativamente em Aristóteles, encontramos também a ideia de que justificar é tornar evidente para os outros a verdade daquilo que afirmamos e, para alcançar esse objetivo, a dimensão retórica da argumentação teria que fornecer elementos normativos que devemos levar em conta. 
Assim, nossa tese é que nas reflexões de Aristóteles sobre a argumentação como prática encontramos a ideia de que esta, enquanto mecanismo de justificação e persuasão, inclui condições normativas lógicas, dialéticas e retóricas. Nessa perspectiva, mais do que definir disciplinas, a obra aristotélica sobre argumentação estaria tratando do fenômeno da comunicação argumentativa em suas três dimensões fundamentais.

A seguir, tentarei ilustrar essa perspectiva, baseando-me em uma leitura um tanto heterodoxa de alguns de seus textos clássicos e, mais concretamente, em uma concepção geral do silogismo como mero argumento, e não como uma forma particular deste.

\section{Lógica formal versus silogística aristotélica}

Nos Analíticos Anteriores (AA), Aristóteles caracteriza o silogismo como um discurso no qual, "quando certas suposições são feitas, alguma coisa distinta delas se segue necessariamente devido à mera presença das suposições como tais" ( $A A$, I. 2, 24b18-20). Nesta obra, Aristóteles estaria desenvolvendo o estudo dos princípios que regem o silogismo, ou seja, sua silogística analítica, como uma teoria formal da inferência, analisando o tipo de relações de conseqüência que ocorrem entre algumas classes de proposições.

Tradicionalmente, o silogismo tem sido entendido como um certo tipo de raciocínio formalmente válido. Em particular, como um conjunto de proposições nas quais, a partir de uma premissa menor (uma proposição que contém como sujeito o termo que por sua vez é o sujeito da conclusão) e uma premissa maior (uma proposição que contém como predicado o termo que por sua vez é o predicado na conclusão), tirase, necessariamente, uma certa conclusão. No entanto, como veremos, esta concepção tradicional do silogismo enfrentaria o fato de que Aristóteles também define o entimema como um silogismo, neste caso, retórico, e não como um silogismo incompleto, tal como a maioria dos intérpretes posteriores havia concordado, partindo de uma concepção claramente dedutivista. Ademais, esse dedutivismo formal entraria em conflito com a importância que Aristóteles deu à condição de que as premissas sejam relevantes para a conclusão. Nossa proposta será, ao contrário, conceber o silogismo como sinônimo de argumento ou processo inferencial, em geral, e não como um tipo particular deste. 
De acordo com Aristóteles, o silogismo procede de premissas universais (AA, I. 27 43b11-14). Conforme a concepção dedutivista tradicional, essas premissas universais foram identificadas como as premissas do silogismo. No entanto, tal como Frede (1987, p. 117) tem argumentado, isso significaria descartar como silogismos exemplos aristotélicos típicos na forma Darii (premissa universal afirmativa, premissa particular afirmativa, conclusão particular afirmativa). Talvez então caberia pensar que tais premissas universais pelas quais "procede" o silogismo são de fato os princípios de inferência que, em sua aplicabilidade geral, conferem justificação a cada proposição deduzida a partir deles. Desse modo, poder-se-ia dizer que uma das causas para que um raciocínio não fosse um verdadeiro silogismo, mas apenas um silogismo aparente, seria que não existe um princípio que garanta que das premissas se tirem a efetivamente a conclusão.

Nos Analíticos Posteriores, Aristóteles afirma que os princípios da uma demonstração devem ser verdadeiros, primários, mais bem conhecidos em si mesmos, anteriores à conclusão e à causa da conclusão. Mas, se notarmos que para Aristóteles existem quatro tipos de causas (material, formal, eficiente e final), teríamos de deduzir que existiriam quatro tipos de princípios do silogismo conforme o tipo de causa estabelecida entre o expresso nas premissas e aquilo que é dito na conclusão. Portanto, sustentar que a validade do silogismo depende da existência de um princípio que garanta a inferência desde as premissas até a conclusão implicaria em admitir que a normatividade silogística não seria exclusivamente de natureza formal, mas que também poderia ser material (relações de relevância), eficiente (relações causais) ou final (raciocínios práticos). Como veremos, seguindo esta interpretação, poderíamos dar sentido à ideia de que os entimemas são silogismos cujos princípios de inferência não seriam formais, mas materiais, teleológicos ou "causais", em nosso sentido moderno de "causa". Da mesma forma, poderíamos definir a noção aristotélica de silogismo perfeito como aquele cujo princípio de inferência é um princípio formal.

Tanto no caso dos silogismos perfeitos como nos dos silogismos imperfeitos, os princípios iriam apenas garantir a validade do silogismo, não a verdade da conclusão: se aplicado a premissas falsas, eles podem servir para deduzir conclusões falsas. Como se sabe, Aristóteles concebe a dedução científica como um silogismo com premissas necessárias, que seriam os primeiros princípios de sua ciência ( $A A$, l.124a29).

Contudo, de alguma forma, sua própria teoria da inferência poderia, por sua vez, se considerar uma ciência cujos primeiros princípios são todos aqueles que Aristóteles resume no capítulo 25 dos Analíticos Anteriores. Então, proposições como a de que toda demonstração será feita por meio de três termos e não mais, ou que todo 
silogismo procede de duas premissas e não mais, ou que adicionar um termo aumenta o número de conclusões possíveis por um número menor que o número original de termos, seriam alguns desses primeiros princípios da silogística, pois tais princípios não apenas garantiriam as inferências silogísticas em geral, mas também seriam as premissas necessárias do próprio raciocínio sobre o silogismo, uma vez caracterizados os conceitos de termo, premissa, conclusão etc ( $A A, 1.4$ 25b 26-27). Desse modo, a silogística aristotélica se apresentaria como uma ciência do raciocínio em geral, enquanto a silogística analítica, em particular, viria a estudar as relações formais que ocorrem entre certos tipos de proposições.

A silogística lidaria, então, com os argumentos em geral, com sua capacidade de mostrar que certas proposições decorrem de outras. Mas, entendida desta forma, ela não estaria identificada com a Lógica Formal, tal como a conhecemos hoje: com efeito, haveria princípios formais que relacionariam algumas proposições a outras, mas também haveria princípios que relacionariam material, causal ou teleologicamente uma premissa à sua conclusão. Os princípios formais seriam necessariamente verdadeiros, mas a própria necessidade não seria uma condição necessária para a validade do silogismo: um bom argumento seria um argumento que segue um princípio, seja uma verdade necessária ou não. O fato de que, para boa parte das questões importantes, carecemos de princípios formais, ou mesmo necessários, isto é, de não termos "demonstrações" para tais questões, não deveria nos levar a pensar que a maneira de resolvê-las não pode ser oferecer bons argumentos. Tal intuição estaria na base do interesse de Aristóteles na argumentação em geral como resposta à demanda de encontrar garantias para nossos juízos sobre o que não admite demonstração.

\section{O entimema como um silogismo retórico}

Segundo Aristóteles, em sua Retórica (Ret.), os entimemas são silogismos retóricos e os silogismos são "o corpo do argumento" (Ret., L.1 1354a). Tradicionalmente, a definição de entimema como silogismo retórico tem sido fonte de dificuldades, principalmente porque não parece evidente que exista uma tradução para a forma silogística, tradicionalmente concebida - isto é, como um argumento composto de premissa maior, premissa menor e conclusão - com base nos exemplos de entimema que Aristóteles oferece. Por isso, tem se sugerido que os entimemas são silogismos incompletos. Tal concepção estaria apoiada em duas razões: por um lado, 
Aristóteles diz explicitamente que os entimemas têm menos premissas do que as demonstrações científicas. Mas, de fato, não é tão evidente que esta fosse para Aristóteles uma condição necessária dos entimemas (ver, por exemplo, Braet, 1999, p. 107). Pode ser que o fato de os entimemas serem silogismos retóricos - isto é, argumentos usados para persuadir um auditório - implique que eles não devam ser muito complexos, se quiserem ser compreendidos e suscitar aceitação.

Se adotamos a concepção tradicional de silogismo, certamente fica difícil reescrever em forma silogística os entimemas que Aristóteles oferece como exemplo. No entanto, qualquer argumento pode se tornar um argumento formalmente válido se Ihe adicionarmos uma condicional redundante cujo antecedente é a premissa ou conjunto de premissas e cujo consequente é a conclusão. Eventualmente, esta condicional poderia ser traduzida como uma afirmação universal, de modo que, efetivamente, pareceria possível entender o entimema como um silogismo incompleto que careceria da premissa maior. Assim, um entimema como "Ela deu a luz, já que tem leite nos seios" deve ser interpretado como:

Premissa maior: todas as mulheres que têm leite nos seios deram a luz

Premissa menor: esta mulher tem leite nos seios

Conclusão: esta mulher deu a luz

Mas o certo é que o princípio que torna válido um silogismo como este é o princípio segundo o qual, se uma propriedade $Q$ se aplica a todos os elementos aos quais se aplica uma propriedade $\mathrm{P}$, logo um elemento que tem a propriedade $\mathrm{P}$ tem a propriedade Q. Este é um princípio formal, aplicável a qualquer elemento e propriedades $\mathrm{P}$ e $\mathrm{Q}$, e como tal, é necessário e a priori. No entanto, o princípio que justificaria o entimema original seria algo como "as mulheres que têm leite nos seios deram a luz”. Este não é um princípio formal, nem necessário, nem a priori , mas uma generalização empírica. Por essa razão, a dedução que garante o primeiro princípio terá propriedades diferentes daquelas que garantem o segundo: na realidade, quando tentamos adaptar um entimema à forma silogística padrão, o que fazemos é modificar seu verdadeiro sentido. Além disso, neste caso, ao tentar conferir uma estrutura formalmente válida ao nosso entimema original, o que fizemos foi transformar um argumento suficientemente sólido em um mau argumento, pois uma de suas premissas (a premissa maior) acaba sendo simplesmente falsa: nem todas as mulheres que têm leite nos seios deram a luz.

Como mencionamos na seção anterior, esta é uma das razões para pensar que o conceito de silogismo excede o de dedução formal e que, portanto, os silogismos não deveriam ser caracterizados como conjuntos de premissa maior, premissa menor e 
conclusão. Ao menos, esta não parece ser a estrutura profunda do entimema, que é todavia definido por Aristóteles como um silogismo retórico.

O que Aristóteles quis dizer então com essa definição? Se pensarmos que a Lógica é o campo da decisão sobre a validade dos argumentos, tanto formal quanto material, teleológico ou causal, poderíamos igualmente conceber que a retórica é o campo da indução de crenças, seja por meio de argumentos ou de outros mecanismos persuasivos. O entimema seria a forma do argumento quando não é concebido como um meio de determinar a correção de uma conclusão, mas como um meio de induzir crenças. Nesse sentido, ao passo que a função do princípio da inferência na justificação de uma conclusão é garantir a dedução desta, sua função na indução de crenças seria motivar nossos juízos. Como uma motivação, não seria uma parte explícita do argumento por meio do qual trataríamos de induzir a crença na conclusão. Por isso, a aparência de "incompletos" dos entimemas em relação ao modelo silogístico tradicional enquanto representação do argumento.

O equívoco de considerar a forma silogística padrão como a estrutura profunda do entimema baseia-se, a meu ver, na crença de que mostrar que uma afirmação decorre de certas premissas aceitas é suficiente para produzir a persuasão de nosso auditório. Mas essa crença é errônea: persuadir alguém de uma afirmação é fazê-lo julgar que tal afirmação é correta. Ao induzir crenças por meio de argumentos, tentamos produzir juízos indiretos, juízos que giram em torno de juízos prévios sobre certas evidências que nos foram apresentadas. Esses juízos prévios nos fornecem razões para inferir, desde que nosso comportamento seja motivado por um princípio de inferência que, se correto, apoiará as conclusões a que chegamos a partir de tais juízos. Sem essa motivação inferencial, o simples fato de julgar que $p$ após julgar que $q$ não seria considerado como um processo de raciocínio, e sim, quando muito, como um caso de associação de ideias.

\section{Conclusão}

Nas últimas seções, tentei tornar plausível a ideia de que a Lógica aristotélica, entendida como o estudo normativo do silogismo em geral, não deve ser simplesmente assimilada à Lógica Formal, tal como a conhecemos hoje, pois, além de incluir condicionantes, como a pertinência, que são estranhos ao conceito de validade desta última, aquela contemplaria a possibilidade de admitir como válidos os silogismos, como os entimemas, cujos princípios de inferência não são formais. 
Como se sabe, a caracterização aristotélica da Dialética faz desta mais um método de investigação do que um modelo de comprovação: na investigação dialética, examinamos certas proposições para estabelecer a sua coerência em relação a outras proposições. É um procedimento crítico; de fato, Aristóteles sustenta que o princípio subjacente à sua prática é o da não contradição. No entanto, o máximo que se pode fazer é mostrar contradições, pois sua capacidade de fazer afirmações é limitada: pode nos ajudar a descartar opiniões problemáticas, mas não a demonstrar o contrário. $\mathrm{A}$ Dialética seria um complemento da demonstração, ao permitir a avaliação dos primeiros princípios de toda ciência (Tóp. 101a 27-28; 101a 34). Nesse sentido, pode-se falar de uma complementaridade entre Lógica e Dialética como disciplinas associadas pelas condições da argumentação enquanto meio para a justificação. No entanto, esse conjunto parece deixar de fora a Retórica, uma vez que seu interesse pela argumentação não se refere à justificação, mas à persuasão.

Apesar disso, também tentei oferecer uma leitura que dissociasse o interesse aristotélico pela retórica do âmbito da deliberação ético-política, insistindo em sua complementaridade no que diz respeito aos métodos de justificação e de prova, uma vez que é possível determinar a racionalidade do discurso, mesmo em áreas em que a demonstração científica é elusiva e, mais importante ainda, porque a justificação requer métodos para mostrar, para persuadir, para tornar evidente o que se está tentando estabelecer.

Assim, não apenas a legitimidade da persuasão, mas também a habilidade de justificar falariam a favor de uma integração das dimensões lógica, dialética e retórica do discurso. No que tange à persuasão, embora sua dimensão retórica manifeste a capacidade comunicativa de induzir crenças, o que pode, indubitavelmente, ser alcançado não apenas pelas boas razões, mas também pelas más razões, o certo é que as condicionantes retórica, dialética e lógica da comunicação devem ser avaliadas, para que se possa determinar a racionalidade do discurso e de nossas reações perante ele, isto caso a nossa aquiescência às palavras do orador conte ou não como um caso de persuasão racional. Da mesma forma, quanto à justificação, a mera correção de nossos argumentos não seria suficiente para produzir conhecimento se não forem conduzidos de maneira adequada e, com isso, servirem para revelar tal conhecimento, isto é, para torná-lo evidente aos nossos semelhantes.

À nossa tese da complementaridade entre Retórica, Dialética e Lógica em Aristóteles opor-se-iam autores como Christian Kock (2009), que defendeu a existência de um tipo de argumentação essencialmente retórica, cuja principal característica seria o tipo de temas de que trata - ou seja, a deliberação sobre decisões práticas, 
principalmente de natureza política. Kock apoia-se no fato de que Aristóteles parecia restringir o escopo da Retórica ao debate sobre assuntos públicos, que são aqueles em que as decisões sobre no que acreditar ou o que fazer admitem mais de duas opções. Desse modo, caberia pensar que o definitório de cada uma dessas disciplinas é o seu campo de competência: enquanto a Retórica pareceria referir-se ao espaço da razão prática, a Lógica e a Dialética seriam, respectivamente, os métodos próprios da demonstração científica e a investigação filosófica.

De minha parte, considero que as caracterizações aristotélicas destes disciplinas não endossam uma diferenciação temática, mas de método e de foco. Cada uma delas cumpriria funções essenciais tanto no campo da razão prática como na razão teórica. Porém, como manifestado anteriormente, meu propósito não foi oferecer uma tese sobre o modo adequado de interpretar Aristóteles, mas sim uma leitura de sua obra que pudesse apontar o caminho para uma integração da Lógica, Dialética e Retórica na Teoria da Argumentação.

Nesta perspectiva que propusemos, a Retórica trataria de estudar a maneira como o discurso se torna um meio para uma decisão razoável. Por esse motivo, ela se afiguraria especialmente adequada na esfera prática, na qual prevalece a necessidade de agir racionalmente, ainda que a verdade e o conhecimento sejam fugidios. $\mathrm{O}$ que a Retórica tornaria possível na esfera prática seria o estudo dos discursos como meio de persuadir seres racionais, a possibilidade de articular essa esfera como âmbito do razoável. De acordo com esta leitura, Aristóteles descartaria a ideia de um conflito entre a Retórica como arte da persuasão, a Dialética como método de investigação e a Lógica como método de prova.

A ideia de que Lógica, Dialética e Retórica são disciplinas complementares inspira o trabalho de muitos teóricos da argumentação na atualidade, desde o interesse da Lógica Informal Canandense pelo componente dialético dos argumentos ao estudo das condições retóricas dos procedimentos argumentativos da Pragmadialética. Mas o fato é que esta visão integradora é bem recente. As obras de Perelman, Toulmin e Hamblin, que hoje são consideradas como a origem da Teoria da Argumentação, podem ser vista, respectivamente, como um questionamento da concepção meramente instrumental da Retórica como arte de persuasão, da concepção da Lógica como mera Lógica Formal ou teoria da inferência formalmente válida e da suposição da impossibilidade de desenvolver um tratamento sistemático das trocas dialéticas e, com isso, das falácias argumentativas. Esses autores destacaram o interesse da argumentação, a necessidade de dedicar esforços ao seu estudo e a escassez e fragilidade dos tratamentos anteriores. Suas propostas foram centrais para o 
desenvolvimento ulterior da Teoria da Argumentação e ainda são profícuas em muitos aspectos. No entanto, na medida em que cada uma delas representa, respectivamente, as origens da perspectiva retórica, lógica e dialética, de alguma forma, elas abundariam na visão dissociada do estudo normativo da argumentação.

Como tentei mostrar, a ideia de considerar a Lógica, a Dialética e a Retórica não como três perspectivas, mas como três dimensões constituintes da argumentação é algo que, de uma forma ou de outra, poderia já ter sido encontrado na obra aristotélica, se a preeminência da Lógica Formal não tivesse dificultado o desenvolvimento de uma teoria normativa de argumentação em linguagem natural. Avançar por este caminho significa assumir que o desenvolvimento de uma teoria normativa adequada requer considerar a prática da argumentação como um composto de propriedades lógicas, dialéticas e retóricas. Na minha opinião, esta seria a leitura mais proveitosa que poderíamos extrair das obras aristotélicas em relação à Teoria da Argumentação: não é um conjunto de obras incorretas, mas sim um projeto epistêmico e cognitivo cujo núcleo constituiria o fenômeno cotidiano e ubíquo da argumentação.

\section{Agradecimentos}

Apresentei algumas ideias deste trabalho no Colóquio de Pesquisa do Departamento de Comunicação, Teoria da Argumentação e Retórica da Universidade de Amsterdã, a convite do Professor Frans van Eemeren. Agradeço a seus membros pelos comentários e sugestões interessantes que fizeram. Além disso, uma primeira versão deste artigo beneficiou-se muito das valiosas críticas e devolutivas dos Professores Javier Rodríguez Alcázar e Luis Vega Reñón. Este trabalho foi financiado pelo Ministério da Educação e Ciência do Governo da Espanha, por meio do programa JAE-doc do CSIC para a contratação de pesquisadores e do financiamento do projeto de pesquisa $\mathrm{FFI} 2008-00085$.

\section{REFERÊNCIAS}

ARISTÓTELES. Obras. Traducción del griego, estudio preliminar, preámbulos y notas por Francisco de P. Samaranch. Aguilar: Madrid, 1964 (Colección Grandes culturas)

BARTH, Else M.; KRABBE, Erik C. W. From Axiom to Dialogue. A philosophical study of logic and argumentation. Berlin; New York: Walter de Gruyter, 1982. 
BENJAMIN, James. The Roots of Informal Logic in Plato. In: WALTON, Douglas N.; BRINTON, Alan (eds.). Historical Foundations of Informal Logic. Ashgate: Aldershot, 1997. p. 25-35

BERMEJO-LUQUE, Lilian. Logic as (normative) inference theory: the logical dimension of argumentation. Informal Logic, Windsor, v. 28, n. 4, p. 315-334, 2008. DOI: https://doi.org/10.22329/il.v28i4.2855

BERMEJO-LUQUE, Lilian. Argumentation Theory and the conception of epistemic justification. Studies in Logic, Grammar and Rhetoric, Białystok, v. 16, n. 29, p. 285-303, 2009.

BRAET, Antoine C. The Enthymeme in Aristotle's Rhetoric: From Argumentation Theory to Logic. Informal Logic, Windsor, v. 19, n. 2, p. 101-107, 1999. DOI: https://doi.org/10.22329/il.v19i2.2322

COVARRUBIAS, Andrés. La dialéctica de Aristóteles: un modelo para la argumentación retórica. Seminarios de filosofia, Santiago, n. 14-15, p. 45-64, 2002. Disponível em: https://repositorio.uc.cl/handle/11534/9948

EEMEREN, Frans H. van; GROOTENDORST, Rob. Speech acts in argumentative discussions. A theoretical model for the analysis of discussions directed towards solving conflicts of opinion. Berlin: Foris, 1984.

FREDE, Michael. Essays in Ancient Philosophy. Minneapolis: University of Minnesota Press, 1987.

GRISWOLD, Charles. Plato on Rhetoric and Poetry. In: ZALTA, Edward N (ed.). The Stanford Encyclopedia of Philosophy (Spring 2004 Edition). Stanford University, 2004. Disponível em: http://plato.stanford.edu/archives/spr2004/entries/plato-rhetoric/

HABERMAS, Jürgen. The Theory of Communicative Action. Tradução: Thomas McCarthy. Boston: Beacon, 1984. v. I: Reason and the Rationalization of Society

HAMBLIN, Charles L. Fallacies. London: Methuen, 1970.

KOCK, Christian. Choice is not true or false: the domain of rhetorical argumentation. Argumentation, Amsterdã, v. 23, n. 1, p. 61-80, 2009. DOI https://doi.org/10.1007/s10503-0089115-X

PERELMAN, Chaïm; OLBRECHTS-TYTECA, Lucie. La nouvelle rhétorique. Traité de l'argumentation. Presses Universitaires de France, Paris. 1958.

PLATO [PLATÃO]. Complete Works. Edição, introdução e notas: John M. Cooper. Indianapolis: Hackett Publishing Company, 1997.

TINDALE, Christopher. Acts of Arguing: A Rhetorical Model of Argument. Albany: Suny Press, 1999.

TOULMIN, Stephen E. The Uses of Argument. Cambridge University Press: Cambridge, 1958.

WALTON, Douglas N. Informal Logic: A Handbook for Critical Argumentation. Cambridge: Cambridge University Press, 1989.

WALTON, Douglas; KRABBE, Erik C. W. Commitment in Dialogue: Basic Concepts of Interpersonal Reasoning. State University of New York Press: New York, 1995. 